\title{
Rendimento de carcaça e qualidade da carne de codornas de corte alimentadas com rações de diferentes níveis de proteína e suplementadas com aminoácidos essenciais
}

\author{
Carcass yield and meat quality of meat quails fed with diets with different levels of protein and \\ essential amino acids supplementation
}

\author{
Sandra Regina Freitas Pinheiro ${ }^{\mathrm{I}^{*}}$ Mariana Almeida Dumont ${ }^{\mathrm{II}}$ Aldrin Vieira Pires ${ }^{\mathrm{I}}$ \\ Cleube Andrade Boari ${ }^{I}$ Jéssica Amaral Miranda II Renata Gomes de Oliveira ${ }^{\text {II }}$ \\ Cátia Borges FerreiraII
}

RESUMO

Objetivou-se avaliar diferentes niveis de proteina bruta e a suplementação de aminoácidos essenciais sobre o rendimento de carcaça e a qualidade da carne de peito de codornas de corte dos 28 aos 42 dias de idade. O delineamento utilizado foi inteiramente casualizado, com cinco tratamentos $(19,21,23,25,27 \%$ PB), cinco repetições e 12 aves (seis fêmeas e seis machos) cada. Aos 42 dias de idade, quatro aves de cada parcela foram abatidas e avaliadas quanto ao rendimento de carcaça quente (RCQ) e resfriada ( $R C F)$, de peito $(R P)$, de coxa e sobrecoxa (RCS), potencial hidrogenionico $(\mathrm{pH})$, capacidade de retenção de água (CRA), perda de peso por cozimento (PPC), cor e luminosidade e maciez objetiva (MO) do músculo. Observou-se efeito dos níveis de PB em todas as variáveis, exceto para CRA e luminosidade da carne de peito. Dessa forma, conclui-se que $19 \%$ de $P B$ e a suplementação de aminoácidos essenciais na ração de codornas de corte seja satisfatório para o rendimento de carcaça, de peito e de qualidade da carne.

Palavras-chave: aminoácidos, carne de peito, Coturnix coturnix coturnix.

\section{ABSTRACT}

The objective was to evaluate different levels of crude protein and essential amino acid supplementation on carcass yield and meat quality of breast meat quails from 28 to 42 days old. The experimental design was in a completely randomized with five treatments $(19,21,23,25,27 \%$ CP), five replicates and 12 birds (six females and six males) each. At 42 days of age four birds from each treatment were slaughtered and evaluated for hot carcass yield (HCY) and cooled (CCY), breast (BY), thigh and drumstick (TDY), hydrogen potential (HP), water holding capacity (WHC), weight loss by cooking (WLC), color and luminosity and objective tenderness (OT) muscle. It was observed effect of CP levels on all variables except for WHC and luminosity of the breast meat.
Thus, it is concluded that 19\% CP and essential amino acids supplementation in the diet of meat quails is satisfactory to the carcass, breast, and meat quality.

Key words: amino acids, breast meat, Coturnix coturnix coturnix.

\section{INTRODUÇÃO}

No Brasil, a produção de codornas é predominantemente voltada para produção de ovos, pois há falta de material genético adequado, além de dados sobre o desempenho e exigências nutricionais de codornas de corte, bem como os da qualidade da carne. Considerando-se o aumento do consumo mundial de carnes, eleva-se o número de consumidores com perfis mais exigentes, que buscam por produtos de qualidade. Portanto, não só o tamanho e o rendimento de carne são relevantes e sim outras características da qualidade da carne devem ser levadas em consideração, como o pH, maciez, capacidade de retenção de água, cor e características sensoriais devem ser avaliados (RODRIGUES et al., 2008).

É amplamente conhecido que a alimentação, linhagem, idade, sexo e processamento de abate interferem com a qualidade da carne. De acordo com RODRIGUES et al. (2008), além da genética e sexo, os níveis de energia, proteína e aminoácidos influem no rendimento e na qualidade

IDepartamento de Zootecnia, Universidade Federal dos Vales do Jequitinhonha e Mucuri (UFVJM), Campus JK, 39100-000, Diamantina, MG, Brasil. E-mail: sandrazoot@yahoo.com.br. *Autor para correspondência.

IPrograma de Pós-graduação em Zootecnia, UFVJM, Diamantina, MG, Brasil. 
da carne de peito de frangos de corte. No entanto, OLIVEIRA et al. (2005) avaliaram o rendimento de carcaça de codornas para corte, alimentadas com dietas com diferentes níveis proteicos e não observaram efeito sobre as características de carcaça consideradas.

Assim, este trabalho foi realizado para avaliar o rendimento da carcaça e cortes, e a qualidade da carne de codornas de corte (Coturnix coturnix coturnix), alimentadas com rações contendo diferentes níveis de proteína bruta e suplementadas com aminoácidos essenciais.

\section{MATERIAL E MÉTODOS}

O experimento foi conduzido no Laboratório de Monogástricos do Departamento de Zootecnia, no Campus JK, da Universidade Federal dos Vales do Jequitinhonha e Mucuri - UFVJM, em Diamantina, M.G., de 14 a 28 de setembro de 2011 e as análises foram realizadas no Setor de Ciências e Tecnologia dos Produtos de Origem Animal/ UFVJM, no período de setembro a outubro de 2011. As codornas utilizadas foram adquiridas do plantel do setor de Melhoramento Genético de Codornas (linhagem LF1) da UFVJM.

Foram utilizadas 300 codornas europeias, dos 28 aos 42 dias de idade, distribuídas em delineamento inteiramente casualizado, com cinco níveis de proteína bruta $(19,21,23,25$ e 27), em cinco repetições de 12 codornas por unidade experimental, sendo seis machos e seis fêmeas. As aves foram alojadas em três baterias de gaiolas de arame galvanizado $(60 \times 60 \times 35 \mathrm{~cm})$, equipadas com comedouros tipo calha e bebedouro tipo copo de pressão.

As rações experimentais foram compostas basicamente por milho e farelo de soja, atendendo as exigências nutricionais das aves em energia, minerais e vitaminas, exceto em proteína bruta, cujos níveis foram variáveis (Tabela 1). Os níveis de proteína bruta foram obtidos por meio de ajustes nas quantidades de milho e farelo de soja, principalmente. Para o estabelecimento dos níveis dos aminoácidos essenciais (metionina + cistina, treonina, triptofano e valina), as rações foram suplementadas com aminoácidos industriais. As proporções mínimas de aminoácido digestível em relação à lisina digestível foram de $69 \%$ para metionina + cistina, $68 \%$ para treonina, $22 \%$ para triptofano e $88 \%$ para valina, sendo estas próximas das recomendações de SILVA \& COSTA (2009). As composições dos ingredientes foram feitas conforme descrito por ROSTAGNO et al. (2005). O fornecimento de água e ração foi à vontade durante todo o período experimental. As temperaturas de máximas e mínimas no interior das instalações foram registradas diariamente, com o uso de termômetros, em cada bateria de gaiolas. Aos 42 dias de idade, foram retiradas quatro aves de cada unidade experimental, sendo duas fêmeas e dois machos, de acordo com o peso médio $( \pm 5 \%)$ da parcela. As aves foram identificadas, insensibilizadas por deslocamento cervical, abatidas e sangradas por dois minutos, após jejum de sólidos por seis horas. A escaldagem das aves foi realizada a uma temperatura controlada de 53 a $55^{\circ} \mathrm{C}$, por 20 a 40 segundos. Logo após, as aves foram evisceradas, retirados os pés e a cabeça, pesadas e colocadas em banho de pré-resfriamento por 25 minutos, a $16^{\circ} \mathrm{C}$, e depois resfriadas a $2^{\circ} \mathrm{C}$ por 24 horas. Após as 24 horas, foram feitos os cortes e as análises de qualidade de carne.

Os rendimentos de peito e coxa mais sobrecoxa foram realizados pelo peso do corte multiplicado por 100, dividido pelo peso vivo médio da parcela. Do mesmo modo, foi feito para carcaça quente e resfriada [\% rendimento de carcaça quente ou resfriada $=($ peso da carcaça quente ou resfriada $\mathrm{x}$ 100) / peso vivo médio da parcela].

As variáveis de qualidade analisadas foram: potencial hidrogeniônico, capacidade de retenção de água, perda de peso por cozimento, cor e luminosidade ( $\left.L^{*}, a^{*}, b^{*}\right)$ e maciez objetiva. Para determinação do $\mathrm{pH}$ (média de três leituras), utilizouse um eletrodo de penetração (Hanna Instruments), diretamente no músculo Pectoralis major.

A medida da capacidade de retenção de água foi realizada utilizando a metodologia descrita por RAMOS \& GOMIDE (2007a). A determinação foi baseada na medição da água liberada, quando aplicada uma pressão sobre o tecido muscular. Para isso, cubos de carne de 0,5 grama foram dispostos entre dois papéis de filtro $(12,5 \mathrm{~cm}$ de diâmetro) e estes entre duas placas de vidro $(12 \times 12 \times 1 \mathrm{~cm})$, sobre o qual foi aplicado o peso de $10 \mathrm{~kg} 5 \mathrm{~min}^{-1}(10 \mathrm{~cm}$ de diâmetro). As amostras de carne de peito, após a pressão, foram pesadas e, por diferença, calculou-se a quantidade de água perdida. O resultado foi expresso em porcentagem de água exsudada em relação ao peso inicial.

A cor dos peitos foi determinada por uso de colorímetro (Minolta CR400), no sistema CIELAB, sendo avaliados os parâmetros L* (luminosidade), a* (teor de vermelho) e $b^{*}$ (teor de amarelo). Os valores $\mathrm{L}^{*}, \mathrm{a}^{*} \mathrm{e} \mathrm{b}^{*}$ foram medidos em três diferentes pontos na superfície ventral e no meio da seção cranial do músculo Pectoralis major. Estas avaliações foram 
Tabela 1 - Composições percentuais das rações para codornas de corte de 28 a 42 dias de idade.

\begin{tabular}{|c|c|c|c|c|c|}
\hline \multirow[t]{2}{*}{ Ingredientes } & \multicolumn{5}{|c|}{-Proteína bruta (\%)- } \\
\hline & 19 & 21 & 23 & 25 & 27 \\
\hline Milho moído & 65,773 & 59,056 & 52,338 & 45,630 & 38,908 \\
\hline Farelo soja (45\%) & 29,588 & 35,171 & 40,759 & 46,318 & 51,910 \\
\hline Óleo soja & 1,713 & 2,845 & 3,975 & 5,108 & 6,241 \\
\hline Sal comum & 0,330 & 0,330 & 0,331 & 0,332 & 0,332 \\
\hline L-Treonina & 0,027 & 0,028 & 0,029 & 0,032 & 0,031 \\
\hline DL-Metionina & 0,144 & 0,177 & 0,210 & 0,245 & 0,276 \\
\hline L-Valina & 0,073 & 0,080 & 0,083 & 0,100 & 0,106 \\
\hline Suplemento Mineral/Vitamínico ${ }^{(1)}$ & 0,400 & 0,400 & 0,400 & 0,400 & 0,400 \\
\hline Fosfato Bicálcico & 0,887 & 0,862 & 0,837 & 0,811 & 0,786 \\
\hline Calcário Calcítico & 1,014 & 1,000 & 0,987 & 0,974 & 0,960 \\
\hline Antioxidante $^{(2)}$ & 0,050 & 0,050 & 0,050 & 0,050 & 0,050 \\
\hline Total & 100,00 & 100,00 & 100,00 & 100,00 & 100,00 \\
\hline Energia Metabolizável (Mcal kg $\left.{ }^{-1}\right)$ & 3,050 & 3,050 & 3,050 & 3,050 & 3,050 \\
\hline Proteína bruta (\%) & 19,00 & 21,00 & 23,00 & 25,00 & 27,00 \\
\hline Metionina digestível (\%) & 0,418 & 0,472 & 0,526 & 0,582 & 0,634 \\
\hline Metionina + cistina digestível (\%) & 0,687 & 0,759 & 0,831 & 0,905 & 0,975 \\
\hline Lisina digestível (\%) & 0,893 & 1,021 & 1,149 & 1,277 & 1,405 \\
\hline Treonina digestível (\%) & 0,669 & 0,739 & 0,810 & 0,882 & 0,950 \\
\hline Triptofano digestível (\%) & 0,205 & 0,232 & 0,259 & 0,287 & 0,314 \\
\hline Valina digestível (\%) & 0,872 & 0,963 & 1,050 & 1,150 & 1,240 \\
\hline Fósforo disponível (\%) & 0,270 & 0,270 & 0,270 & 0,270 & 0,270 \\
\hline Cálcio (\%) & 0,700 & 0,700 & 0,700 & 0,700 & 0,700 \\
\hline Sódio (\%) & 0,150 & 0,150 & 0,150 & 0,150 & 0,150 \\
\hline
\end{tabular}

${ }^{(1)}$ Por kg de produto: Manganês, 75mg; ferro, 50mg; zinco, 70mg; cobre, 8,50mg; cobalto, 2mg; iodo, 1,5mg e veículo q.s.p. 1.000g. Vit. A, 12.000UI; vit. $\mathrm{D}_{3}, 2.200 \mathrm{UI}$; vit. E, 30UI; vit. $\mathrm{B}_{1}, 2,2 \mathrm{mg}$; vit. $\mathrm{B}_{2}, 6 \mathrm{mg}$; vit. $\mathrm{B}_{6}, 3,3 \mathrm{mg}$; vit. $\mathrm{B}_{12}, 16 \mathrm{mg}$; niacina, $2.500 \mathrm{mg}$; ácido pantotênico, $13 \mathrm{mg}$; vit. $\mathrm{K}_{3}, 2,5 \mathrm{mg}$; ácido fólico, $1 \mathrm{mg}$; selênio, $0,12 \mathrm{mg}$; antioxidante, $10 \mathrm{mg}$ e veículo q.s.p. - $1.000 \mathrm{~g}$. ${ }^{(2)}$ Butil hidroxitolueno.

feitas conforme metodologia proposta por RAMOS \& GOMIDE (2007c).

Para as análises de perda de peso por cocção, amostras de filés íntegros foram embaladas em papel metalizado, sendo cozidas em uma chapa metálica de dupla face, com aquecimento em ambas as faces, préaquecida e regulada para $150^{\circ} \mathrm{C}$, permanecendo por 4 minutos para cada lado do filé, num total de 8 minutos de cozimento ou até atingir uma temperatura interna de 82 a $85^{\circ} \mathrm{C}$. Após o cozimento, os filés foram retirados do papel metalizado e resfriados sobre papel absorvente à temperatura ambiente. Posteriormente, as amostras foram pesadas para averiguação da perda de peso antes e após cozimento. A diferença entre o peso inicial (peito in natura) e final (peito cozido) correspondeu à perda de peso por cozimento. Para a avaliação da força de cisalhamento, foi utilizado o texturômetro Stable Micro Systems TAXT 2 plus, equipado com probe blade set V Warner Bratzler. O equipamento foi calibrado com peso-padrão de $5 \mathrm{~kg}$ e padrão rastreável. A velocidade de descida e corte do dispositivo foi ajustado a $200 \mathrm{~mm} \mathrm{~min}^{-1}$ (AMSA, 1995), sendo as amostras as mesmas utilizadas na determinação da perda de peso por cozimento. Foi retirada uma amostra por filé de peito na forma de paralelepípedos com $1 \times 1 \times 2 \mathrm{~cm}$ (altura, largura e comprimento), as quais foram colocadas com as fibras orientadas no sentido perpendicular à lâmina da probe Warner-Blatzler (RAMOS \& GOMIDE, 2007b).

Os dados foram submetidos à análise de variância e inicialmente testados e atendidas todas as pressuposições. Os níveis de proteína bruta foram desdobrados em regressão polinomial e as análises estatísticas foram realizadas utilizando-se o programa SAEG (2000).

\section{RESULTADOS E DISCUSSÃO}

No decorrer do período experimental, as temperaturas médias de mínimas e máximas, 
registradas no interior do galpão, foram de 18,8 e $24,5^{\circ} \mathrm{C}$, respectivamente.

Para as características de rendimento de carcaça quente e resfriada e rendimento de peito, foi observado efeito $(\mathrm{P} \leq 0,05)$ dos níveis de proteína bruta (Tabela 2).

Os rendimentos de carcaças quente e resfriada apresentaram $(\mathrm{P} \leq 0,01)$ comportamento linear decrescente, segundo as equações: $\mathrm{RCQ}=85,2349$ $0,5687 \mathrm{~PB} \quad\left(\mathrm{R}^{2}=0,91\right)$ e $\mathrm{RCF}=85,1355-0,4579$ PB $\left(\mathrm{R}^{2}=0,96\right)$, respectivamente, em função dos crescentes níveis proteicos das rações. Isso indica que, dentro do intervalo estudado, à medida que se eleva o nível proteico da ração, houve uma queda nos rendimentos de carcaças. SILVA et al. (2006), trabalhando com redução de PB e suplementação aminoacídica para codornas de corte, verificaram que, ao atender a exigência da metionina + cistina, foi possível reduzir a PB de 24 para 19,2\%, no período de 22 a 42 dias, independentemente da suplementação de lisina. CORRÊA et al. (2007) relataram que baixos níveis proteicos $(22 \%)$ não são prejudiciais às codornas de corte durante a fase final de crescimento, uma vez que estas devem ingerir alimentos para atender suas necessidades nutricionais e, em consequência, apresentar semelhante eficiência de transformação em peso.

$\mathrm{O}$ rendimento de peito das codornas decresceu linearmente $(\mathrm{P}<0,01)$ em função dos crescentes níveis proteicos das rações, de acordo com a equação: $\mathrm{RP}=40,3103-0,4287 \mathrm{~PB}\left(\mathrm{R}^{2}=0,97\right)$. OTUTUMI et al. (2009), ao avaliarem rações com níveis proteicos de 15 a 30\% para codornas de corte, relataram que o rendimento de peito apresentou melhores resultados com o nível de $26,47 \%$ de PB. Pelo exposto, não se justifica o uso de elevados níveis proteicos nas rações de codornas de corte, pois, além de elevarem os custos de produção, acarreta em incremento calórico corporal desnecessário para o animal, já que, com o excesso de proteína, o aminoácido excedente às exigências deverá ser catabolizado, havendo um custo energético para que este processo ocorra, o que pode explicar piores resultados em rendimento de partes com maiores níveis de proteína bruta na ração de codornas de corte, aos 42 dias de idade. CORRÊA (2006), ao avaliar níveis de $\mathrm{PB}$ que variavam de 23 a $33 \%$, não encontrou efeito significativo sobre o rendimento de carcaça eviscerada, de coxa e peito. De acordo com SILVA et al. (2006), para codornas europeias na fase de 22 a 42 dias de idade, a ração deve conter $2.900 \mathrm{kcal}$ de EMAn, 19,2\% de proteína, 0,9\% de metionina + cistina e $0,95 \%$ de lisina.

As formulações de rações com o fornecimento de aminoácidos essenciais de acordo com as exigências das aves permitem a utilização de rações com níveis de proteína bruta inferiores. Assim, pode-se melhorar o desempenho do animal e redução nos custos produção, devido ao aumento na eficiência de utilização da proteína, visto que o máximo uso de aminoácidos será para a síntese proteica e o mínimo como fonte de energia.

Os níveis de proteína bruta influenciaram $(\mathrm{P} \leq 0,05)$ as características de qualidade da carne de codornas de corte aos 42 dias de idade, como: $\mathrm{pH}$, maciez objetiva, perda de peso por cozimento e tendência de cor do peito para o vermelho. Não havendo efeito significativo $(\mathrm{P}>0,05)$ para as demais características avaliadas (Tabela 3 ).

$\mathrm{O} \mathrm{pH}$ do peito 24 horas post mortem apresentou efeito linear crescente $(\mathrm{P} \leq 0,05)$, de acordo com a equação: $\mathrm{pH}=5,568+0,00814 \mathrm{~PB}$. Isso significa que, quando se eleva o nível de proteína bruta na ração, os valores de $\mathrm{pH}$ aumentam. A carne de peito de frango apresenta $\mathrm{pH}$ final (após 24 horas) entre 5,6 e 5,9 em carne normal (VENTURINI et al., 2007). As médias do $\mathrm{pH}$ final da carne de peito das codornas de corte observadas mostraram-se com valores que se enquadram na faixa de $\mathrm{pH}$ estipulada para carne de peito de frango normal.

A perda de peso por cozimento apresentou efeito quadrático $(\mathrm{P} \leq 0,01), \mathrm{PPC}=-63,762+8,049 \mathrm{~PB}-$ $0,172 \mathrm{~PB}^{2}$ e a estimativa do nível de $\mathrm{PB}$ de $23,39 \%$

Tabela 2 - Médias do rendimento de carcaça quente (RCQ), carcaça resfriada (RCF), peito (RP) e de coxa + sobrecoxa (RCS) de codornas de corte aos 42 dias de idade, alimentadas com diferentes níveis de proteína bruta e suplementadas com aminoácidos essenciais.

\begin{tabular}{|c|c|c|c|c|c|c|c|}
\hline \multirow{2}{*}{ Característica } & \multicolumn{7}{|c|}{-Proteína bruta (\%)-- } \\
\hline & 19 & 21 & 23 & 25 & 27 & Signif. & $\mathrm{CV} \%$ \\
\hline RCQ (\%/ave) & 73,71 & 74,01 & 72,39 & 70,68 & 69,84 & 0,034 & 3,10 \\
\hline $\mathrm{RCF}(\% /$ ave $)$ & 76,19 & 75,85 & 74,37 & 73,96 & 72,61 & 0,090 & 2,77 \\
\hline RP (\%/ave) & 31,96 & 31,43 & 30,72 & 29,33 & 28,77 & 0,002 & 3,89 \\
\hline RCS (\%/ave) & 17,67 & 18,60 & 17,51 & 17,70 & 17,74 & 0,248 & 4,48 \\
\hline
\end{tabular}

$\mathrm{CV}=$ Coeficiente de variação; Signif = Nível de significância do teste $\mathrm{F}$. 
Tabela 3 - Médias do pH, capacidade de retenção de água (CRA), perda de peso por cozimento (PPC), maciez objetiva (MO), luminosidade $\left(\mathrm{L}^{*}\right)$, tendência de cor para o vermelho $\left(\mathrm{a}^{*}\right)$ e tendência de cor para o amarelo $\left(\mathrm{b}^{*}\right)$ no peito de codornas de corte alimentadas com diferentes níveis de proteína bruta e suplementadas com aminoácidos essenciais.

\begin{tabular}{|c|c|c|c|c|c|c|c|}
\hline \multirow{2}{*}{ Característica } & \multicolumn{7}{|c|}{ Proteína bruta (\%)----- } \\
\hline & 19 & 21 & 23 & 25 & 27 & Signif. & CV $(\%)$ \\
\hline $\mathrm{pH}$ & 5,72 & 5,71 & 5,8 & 5,78 & 5,78 & 0,037 & 1,85 \\
\hline CRA $(\%)$ & 39,00 & 45,00 & 46,00 & 41,00 & 37,00 & 0,316 & 12,93 \\
\hline PPC (\%) & 27,76 & 29,71 & 33,78 & 28,14 & 27,77 & 0,001 & 18,85 \\
\hline $\mathrm{MO}\left(\mathrm{kgf} \mathrm{g}^{-1}\right)$ & 1,55 & 1,48 & 1,47 & 1,61 & 1,84 & 0,061 & 27,92 \\
\hline $\mathrm{L}^{*}$ & 47,91 & 47,32 & 46,69 & 48,20 & 46,8 & 0,439 & 6,41 \\
\hline$a^{*}$ & 12,91 & 14,59 & 14,78 & 14,41 & 15,56 & 0,004 & 14,75 \\
\hline$b^{*}$ & 7,44 & 7,63 & 7,48 & 7,78 & 7,79 & 0,898 & 18,29 \\
\hline
\end{tabular}

$\mathrm{CV}=$ Coeficiente de variação; Signif. = Nível de significância do teste F.

maximiza esta variável, o que significa uma carne mais dura neste nível.

De acordo com a equação quadrática obtida $\left(\mathrm{MO}=7,799-0,585 \mathrm{~PB}+0,0135 \mathrm{~PB}^{2}\right)$, o nível de $21,67 \% \mathrm{~PB}$ apresentou menor valor $\left(1,46 \mathrm{kgf} \mathrm{g}^{-1}\right) \mathrm{de}$ maciez objetiva para a carne de peito das codornas, o que representa uma carne mais macia, sugerindo que a carne de codorna é mais macia que a carne de frango de corte. LYON et al. (1985) utilizaram, como referência para carne de frango macia, o valor de $7,5 \mathrm{kgf} \mathrm{g}^{-1}$, enquanto SIMPSON \& GOODWIN (1974) de $8,0 \mathrm{kgf}^{-1}$ como limite, acima do qual a carne seria considerada dura.

Para a coloração da carne das codornas, o teor de vermelho $\left(\mathrm{a}^{*}\right)$ apresentou efeito linear crescente $(\mathrm{P} \leq 0,01)$, com a equação $\mathrm{a}^{*}=8,131+0,27858 \mathrm{~PB}$. Portanto, com a elevação do nível de proteína na ração, a carne de peito se tornou mais escura. Em estudos realizados por SANTOS et al. (2005), avaliando a coloração de carne de peito de linhagens comerciais de frango de corte e aves caipiras, os autores evidenciaram resultados com valores médios de teor de vermelho de 2,66 e 3,44, respectivamente. A carne de avestruz tem apresentado dados em relação à cor, variando de $27,35 \leq \mathrm{L} * \leq 37,5 ; 13,65 \leq \mathrm{a} * \leq 21,60$; e $0,06 \leq b^{*} \leq 5,87$ (HOFFMAN, 2008). Comparando os parâmetros descritos para a carne de avestruz com o obtido neste trabalho, observa-se que a carne de codornas possui maior luminosidade e teor de amarelo que a de avestruz, no entanto, menor teor de vermelho. Assim, sugere-se que a carne de codorna possui aparência mais luminosa e clara que a de avestruz.

\section{CONCLUSÃO}

Codornas de corte não requerem mais do que $19 \%$ de proteína na ração, no período de 28 a 42 dias de idade, para obtenção de satisfatório rendimento de carcaça quente e resfriada e de peito, bem como para as características de qualidade da carne de peito, desde que a ração seja suplementada com aminoácidos limitantes.

\section{AGRADECIMENTOS}

Agradecemos à Fundação de Amparo a Pesquisa do Estado de Minas Gerais (FAPEMIG), pelo apoio financeiro, e à Ajinomoto do Brasil, pela doação dos aminoácidos.

\section{COMITÊ DE ÉTICA E BIOSSEGURANÇA}

O experimento foi aprovado pelo Comitê de Ética sobre o Uso de Animais (CEUA) da Universidade Federal dos Vales do Jequitinhonha e Mucuri (UFVJM).

\section{REFERÊNCIAS}

AMERICAN MEAT SCIENCE ASSOCIATION (AMSA). Research guidelines for cookery sensory and instrumental tenderness measurement of fresh meat. Chicago, 1995. 48p.

CORRÊA, G.S.S. et al. Exigências de proteína bruta e energia metabolizável em codornas de corte durante a fase de crescimento. Arquivo Brasileiro de Medicina Veterinária e Zootecnia, v.59, n.2, p.488-494, 2007. Disponível em: <http:// www.scielo.br/scielo.php?script $=\mathrm{sci}$ issuetoc $\& \mathrm{pid}=0102$ 093520070002\&lng=pt\&nrm=iso>. Acesso em: 12 nov. 2011.

CORRÊA, G.S.S. Exigências nutricionais de diferentes grupos genéticos de codornas de corte. 2006. 175f. Tese (Doutorado em Produção Animal) - Curso de Pós-graduação em Zootecnia Universidade Federal de Minas Gerais, MG.

HOFFMAN, L.C. The yield and nutritional value of meat from African ungulates, camelidae, rodents, ratites and reptiles. Meat Science, v.80, p.94-100, 2008. Disponível em: <http://www. sciencedirect.com/science/journal/03091740>. Acesso em: 12 set. 2011. doi: 10.1016/j.meatsci.2008.05.018.

LYON, C.E. et al. $\mathrm{pH}$ and tenderness of broiler breast meat deboned various times after chilling. Poultry Science, v.64, n.2, p.307- 
310, 1985. Disponível em: <http://ps.fass.org/content/64/2/307. abstract?sid $=5 \mathrm{fe} 493 \mathrm{ff}-236 \mathrm{e}-492 \mathrm{f}-9 \mathrm{ee} 1-2979513 \mathrm{edb} 3 \mathrm{~d}>$. Acesso em 12 set. 2011. doi: 10.3382/os.0640307.

OLIVEIRA, E.G. et al. Avaliação do rendimento de carcaça de codornas para corte alimentadas com dietas com diferentes níveis proteicos. Archives of Veterinary Science, v.10, n.3, p.42-45, 2005. Disponível em: <http://ojs.c3sl.ufpr.br/ojs2/index.php/ veterinary/article/view/5116/3863>. Acesso em: 27 out. 2011.

OTUTUMI, L.K. et al. Efeito do probiótico sobre o desempenho, rendimento de carcaça e exigências de proteína bruta. Revista Brasileira de Zootecnia, v.38, n.2, p.299-306, 2009. Disponível em: <http://www.scielo.br/scielo.php?script= sciarttext\&pid=S1516-35982009000200012>. Acesso em: 27 out. 2011. doi: 10.1590/S1516-35982009000200012.

RAMOS, E.M.; GOMIDE, L.A.M. Avaliação da qualidade de carnes - Fundamentos e metodologias. In: Avaliação de carnes anormais: condições PSE e DFD. Viçosa: UFV, 2007. Cap.10, p.531-575a.

RAMOS, E.M.; GOMIDE, L.A.M. Avaliação da qualidade de carnes - Fundamentos e metodologias. In: . Avaliação instrumental da textura. Viçosa: UFV, 2007. Cap.9, p.455-530b.

RAMOS, E.M.; GOMIDE, L.A.M. Avaliação da qualidade de carnes - Fundamentos e metodologias. In: Avaliação objetiva da cor. Viçosa: UFV, 2007. Cap.7, p.287-374c.

RODRIGUES, K.F. et al. Qualidade da carne de peito de frangos de corte recebendo rações com diferentes relações lisina digestível:proteína bruta. Revista Brasileira de Zootecnia, v.37, n.6, p.1023-1028, 2008. Disponível em: <http://www.scielo.br/ pdf/rbz/v37n6/v37n6 a11.pdf $>$. Acesso em: 18 set. 2011. doi: 10.1590/S1516-35982008000600011.

ROSTAGNO, H.S. et al. Tabelas brasileiras para aves e suínos (composição de alimentos e exigências nutricionais). Viçosa: UFV, 2005. 186p.

SAEG. Sistema para análise estatística, versão 8.0. Viçosa-MG: Fundação Artur Bernardes, 2000. 142p.

SILVA, E.L. et al. Redução dos níveis de proteína e suplementação aminoacídica em rações para codornas européias (Coturnix coturnix coturnix). Revista Brasileira de Zootecnia, v.35, n.3, p.822-829, 2006. Disponível em: <http://www.scielo.br/pdf/rbz/ v34n5/26640.pdf>. Acesso em: 12 maio 2012.

SILVA, J.H.V.; COSTA, F.G.P. Tabelas para codornas japonesas e européias. Jaboticabal, SP: FUNEP, 2009. 107p.

SIMPSON, M.D.; GOODWIN T.L. Comparison between shear values and test panel scores for predicting tenderness of broilers. Poultry Science, v.53, n.6, p.2042-2046, 1974. Disponível em: $<$ http://ps.fass.org/content/53/6/2042.abstract?sid=e682dec695cc-438c-bf69-e3155d23817f>. Acesso em: 18 set. 2011. doi: $10.3382 /$ ps.0532042.

VENTURINI, K.S. et al. Características da carne de frango. Espírito Santo: Pró-Reitoria de Extensão, Programa Institucional de Extensão, 2007. 7p. (Boletim Técnico, 7). Disponível em: $<$ http:// www.agais.com/telomc/b01307_caracteristicas_carnefrango.pdf $>$. Acesso em: 12 set. 2011. 